\title{
Multiple Influence Factor Sensitivity Analysis and Height Prediction of Water-Conducting Fracture Zone
}

\author{
Xiaobin Li $\mathbb{D}^{1},{ }^{1}$ Quansheng Li, ${ }^{1,2}$ Xuhui Xu $\mathbb{D}^{1},{ }^{1}$ Yongqiang Zhao, ${ }^{2}$ and Peng $\mathrm{Li}^{1}$ \\ ${ }^{1}$ School of Energy and Mining Engineering, China University of Mining and Technology (Beijing), Beijing 100083, China \\ ${ }^{2}$ State Key Laboratory of Water Resource Protection and Utilization in Coal Mining, Beijing 100011, China \\ Correspondence should be addressed to Xiaobin Li; 1xb162197@126.com and Xuhui Xu; 1442897499@qq.com
}

Received 27 September 2020; Revised 30 October 2020; Accepted 3 April 2021; Published 18 April 2021

Academic Editor: Qiqing Wang

Copyright (C) 2021 Xiaobin Li et al. This is an open access article distributed under the Creative Commons Attribution License, which permits unrestricted use, distribution, and reproduction in any medium, provided the original work is properly cited.

\begin{abstract}
To explore the influence law and sensitivity of various factors on the height of the water-conducting fracture zone, and further predict the development height of the water-conducting fracture zone, taking the field survey and collected actual measured data as the research foundation, establishing mathematical model, regression analysis, and field measurement were adopted comprehensively. Based on the Data Processing System (DPS), influence factors of the development height of the waterconducting fracture zone were analyzed. By introducing sensitivity coefficient, a sensitivity quantification mathematical model was established, and sensitivity ranking was obtained. The regression relationship between each factor and the height of the water-conducting fracture zone was obtained by single factor analysis. Based on this, the prediction formula was proposed and successfully used in the field practice. Results show that the sensitivity coefficient of mining thickness, ratio coefficient of hard rock lithology, mining depth, and length of working face was $0.75,0.69,0.66$, and 0.58 , respectively. The dispersion degree of working face length and mining depth was greater than that of ratio coefficient of hard rock lithology and mining thickness. To some extent, it also reflects that the sensitivity of working face length and mining depth to the height of the water-conducting fracture zone was the weakest, which was consistent with the previous conclusions. Using the multiple regression mathematical model, a nonlinear statistical relationship between the height of the water-conducting fracture zone and ratio coefficient of hard rock lithology, mining thickness, working face length, and mining depth was obtained. This research provides some scientific basis and guidance for safe and efficient underwater mining.
\end{abstract}

\section{Introduction}

When coal seam is mined, the overlying strata of working face will undergo significant movements, resulting in the occurrence of the collapse zone and fracture zone in the rock strata $[1,2]$. If there is a connection between the fractures, it will cause water damage in the working face. Therefore, the height of the water-conducting fracture zone can be reasonably predicted, which is conducive to the realization of safe underwater coal mining [3-6]. For a long time, many experts and scholars have carried out relevant research and exploration on the development height of the water-conducting fracture zone and achieved good results. Based on system theory and energy conservation principle, Zhang et al. [7] proposed to adopt the "mining-burst" physical model for the prediction of the height of water-conducting fracture zone. $\mathrm{Xu}$ et al. [8] proposed a method to predict the height of the water-conducting fracture zone based on the position of key strata by studying the relationship between the position of key strata and the height of the water-conducting fracture zone. Shi et al. [9] proposed that the working face span and aquifer water pressure have a controlling effect on the height of the water-conducting fracture zone under the condition of large mining depth based on the "upper four zones" theory in stope. Lai et al. [10] and Yang et al. [11] comprehensively used onsite measurement and numerical simulation to reasonably predict the height of the water-conducting fracture zone with the special geological conditions of the three soft coal seams and the soft overburden of the thick loose layer. Li et al. [12] carried out some research on the evaluation of the adaptability of groundwater reservoir based on the height of the water-conducting fracture zone, which provide 
scientific guidance for the site selection of groundwater reservoir in the Shendong mining area. Wang et al. [13] established a mechanical model capable of predicting the height of the water-conducting fracture zone based on the type of rock layer and its bearing capacity and deformation capacity and obtained good application results in Daliuta coal mine. Generally speaking, the methods of the predicting waterconducting fracture zone include theoretical analysis, empirical formula calculation, field measurement, numerical analysis, and physical simulation. Due to the complexity of rock mass structure and onsite geological conditions, the results obtained are often very different from the actual measured values on site, and previous studies have limitations. Therefore, how to accurately and comprehensively predict the development height of the water-conducting fracture zone has been the direction that mining scholars are constantly exploring.

At present, China's calculation of the development height of the water-conducting fracture zone is mainly based on the "Code for the Preservation and Pressing of Coal Pillars in Buildings, Water Bodies, Railways, and Main Wells and Roadways" (referred to as "three under" rules) [14]. However, the development height of the water-conducting fracture zone is affected by many factors such as geological production conditions, overlying strata combination structure, and coal mining technology $[15,16]$. Due to the continuous innovation of mining technology, the mining method and burial depth of coal seam have changed. As a result, the height of the water-conducting fracture zone in some mining areas is not completely consistent with the prediction formula $[17,18]$. In view of this, using the formula of "three under" rules to calculate the height of the waterconducting fracture zone cannot meet the safety production needs of coal mines.

The calculation formula given in the code only considers the influence of coal seam thickness, which is not comprehensive. Theory and practice show that the development height of the water-conducting fracture zone is also influenced by many factors such as rock combination structure type, working face size, and mining depth. These factors are complex, difficult to quantify, and belong to nonlinear problems [19-22]. At the same time, there are relatively few quantitative studies on the sensitivity of these influence factors to the development height of the water-conducting fracture zone.

Through summarizing relevant literatures and investigations, the data of the height of the water-conducting fracture zone in the Shendong mining area and surrounding coal mines were collected, and multiple influence factor sensitivity and height prediction of the water-conducting fracture zone were analyzed. This research has important guiding significance for the realization of safe coal mining underwater and mine water control.

\section{Influence Factors of the Height of the Water- Conducting Fracture Zone}

2.1. Ratio Coefficient of Hard Rock Lithology. Ratio coefficient of hard rock lithology refers to the ratio of the cumulative

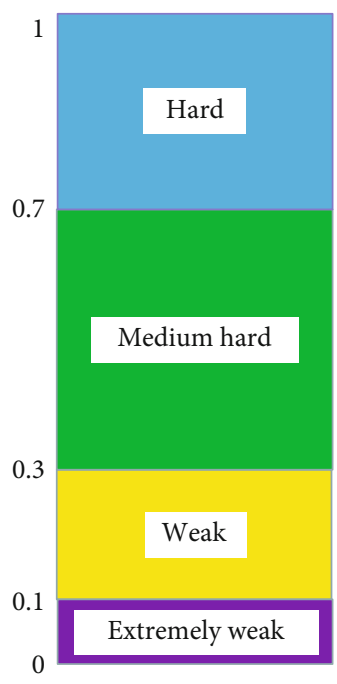

FIGURE 1: Classification of rock stability based on ratio coefficient of hard rock lithology.

thickness of hard rock to the statistical height within the statistical height of the water-conducting fracture zone of overburden, expressed by $b$. It can avoid the problems of statistically combined rock strata structure types and uncertain uniaxial compressive strength, which can better reflect the hard degree of roof and the combined rock strata structure types [23]. As shown in Figure $1,0 \leq b \leq 0.1$ stands for extremely weak roof; $0.1<b \leq 0.3$ stands for weak roof; 0.3 $<b \leq 0.7$ stands for medium hard roof; $0.7<b \leq 1$ stands for hard roof [24].

2.2. Mining Thickness. Mining thickness is the basic factor affecting the development height of the water-conducting fracture zone. In the traditional calculation formula, it is the only index to predict the development height of the water-conducting fracture zone. According to the theory of strata control and previous measured data of other mining areas, in the case of the same overlying strata type, the development height of the water-conducting fracture zone increases with the increase of mining thickness. When mining thickness is small, the increase degree is relatively significant. When mining thickness is large, the increase degree gradually decreases (Figure 2).

2.3. Length of Working Face. The influence of working face length on overburden failure height depends on whether the mining range reaches critical extraction. In the case of subcritical extraction, the height of the water-conducting fracture zone increases with the increase of working face length. After reaching critical extraction, the development height of the water-conducting fracture zone will not change with the working face length.

2.4. Mining Depth. Within a certain range, the increase of mining depth will cause the increase of in situ stress and overburden failure height. However, when mining depth reaches a certain value, the development height of the water-conducting fracture zone will not increase with the 


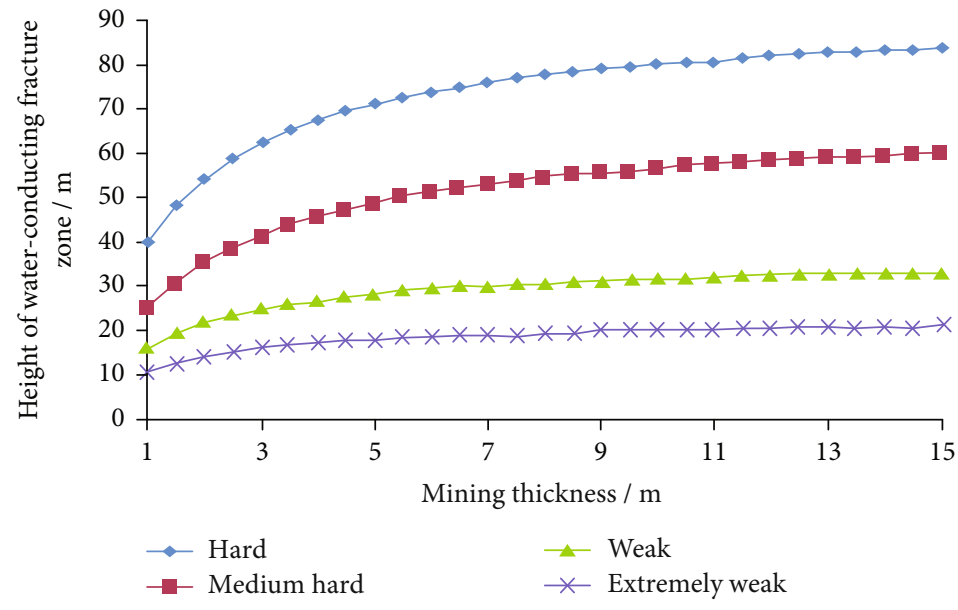

FIGURE 2: Relationship between mining thickness and height of the water-conducting fracture zone with different lithology [25].

increase of mining depth (Figure 3). This is because when mining depth reaches a certain level, mining unloading fracture is closed in a short time due to high in situ stress, and the height of the water-conducting fracture zone will basically not change [26].

\section{Measured Data of the Height of the Water- Conducting Fracture Zone}

Since the traditional empirical formula only considers the thickness of coal seam, in order to more comprehensively study the influence law and sensitivity of various factors on the development height of water-conducting fracture zone, the data of the height of the water-conducting fracture zone in the Shendong mining area and surrounding coal mines were collected by summarizing the relevant literature [2729] and investigation, as shown in Table 1.

\section{Sensitivity Analysis}

4.1. Construction of the Mathematical Model. Based on the Data Processing System (DPS) and data in Table 1, the sensitivity quantification mathematical model is established. In this paper, initial value processing is adopted, namely,

$$
x_{i}^{\prime}(k)=\frac{x_{i}(t)}{x_{i}(1)}, k=1,2, \cdots, n
$$

In the formula, $x_{i}^{\prime}(k)$ is the initial value, $t$ stands for different groups, $i$ is the index number affecting the development height of the water-conducting fracture zone, and $k$ represents the number of measured data.

In this paper, the sensitivity formula of various factors to the development height of the water-conducting fracture zone is established:

$$
Y\left(X_{0}, X_{i}\right)=\frac{1}{n} \sum_{k=1}^{n} Y\left(x_{0}(k), x_{i}(k)\right)
$$

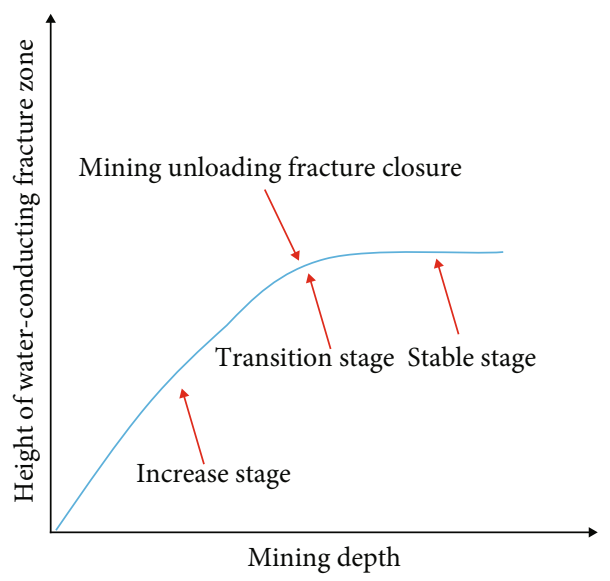

Figure 3: Dynamic evolution stage of the height of the waterconducting fracture zone with mining depth.

In the formula, $Y\left(X_{0}, X_{i}\right)$ is the sensitivity coefficient of the factor $x_{i}(k)$ to the development height of the water-conducting fracture zone $x_{0}(k)$ when the data is $k$ and satisfies

$$
Y\left(x_{0}(k), x_{i}(k)\right)=\frac{\min _{i} \min _{k}\left|x_{0}(k)-x_{i}(k)\right|+\xi \max _{i} \max _{k}\left|x_{0}(k)-x_{i}(k)\right|}{\left|x_{0}(k)-\mathrm{x}_{\mathrm{i}}(k)\right|+\xi \max _{i} \max _{k}\left|x_{0}(k)-x_{i}(k)\right|} .
$$

In the formula, $\xi$ is the resolution coefficient. Reference [30] gives calculation formula of the resolution coefficient:

$$
\int_{0}^{+\infty} \frac{1}{(1+\xi)^{2}} d \xi=-\left.\frac{1}{1+\xi}\right|_{0} ^{+\infty}=1
$$

According to equation (4), when $\xi \in(0.32,0.59)$, the resolution coefficient can best reflect the sensitivity coefficient. In this paper, the resolution coefficient is 0.5 . 
TABLE 1: Data of the height of the water-conducting fracture zone and influence factors.

\begin{tabular}{|c|c|c|c|c|c|c|}
\hline Number & $\begin{array}{l}\text { Borehole number } \\
\text { of working face }\end{array}$ & $\begin{array}{l}\text { Ratio coefficient of } \\
\text { hard rock lithology }\end{array}$ & $\begin{array}{l}\text { Mining } \\
\text { thickness } / \mathrm{m}\end{array}$ & $\begin{array}{l}\text { Length of working } \\
\text { face } / \mathrm{m}\end{array}$ & $\begin{array}{l}\text { Mining } \\
\text { depth/m }\end{array}$ & $\begin{array}{l}\text { Height of the water-conducting } \\
\text { fracture zone/m }\end{array}$ \\
\hline 1 & 93104 & 0.46 & 3.0 & 374.0 & 114.0 & 45.7 \\
\hline 2 & 12403 & 0.44 & 2.0 & 297.5 & 110.9 & 35.7 \\
\hline 3 & 22111-1 & 0.46 & 2.8 & 234.6 & 311.5 & 41.1 \\
\hline 4 & $22111-2$ & 0.45 & 2.8 & 234.6 & 299.0 & 39.2 \\
\hline 5 & 12401-1 & 0.70 & 4.6 & 266.0 & 247.0 & 154.0 \\
\hline 6 & $12401-2$ & 0.68 & 4.4 & 266.0 & 244.0 & 140.5 \\
\hline 7 & $12406-1$ & 0.53 & 4.4 & 294.0 & 181.7 & 74.0 \\
\hline 8 & $12406-2$ & 0.56 & 4.4 & 294.0 & 180.0 & 89.5 \\
\hline 9 & 22101 & 0.69 & 3.0 & 325.0 & 327.0 & 146.0 \\
\hline 10 & 12304-1 & 0.50 & 3.8 & 256.8 & 299.0 & 55.7 \\
\hline 11 & $12304-2$ & 0.48 & 3.8 & 256.8 & 299.3 & 53.9 \\
\hline 12 & 12511-1 & 0.57 & 5.6 & 319.1 & 242.1 & 93.1 \\
\hline 13 & $12511-2$ & 0.62 & 7.4 & 319.1 & 271.0 & 111.1 \\
\hline 14 & 42106-1 & 0.70 & 6.6 & 309.0 & 426.1 & 158.5 \\
\hline 15 & $42106-2$ & 0.55 & 3.0 & 309.0 & 344.1 & 79.4 \\
\hline 16 & $42106-3$ & 0.70 & 6.6 & 309.0 & 422.0 & 154.4 \\
\hline 17 & $42106-4$ & 0.54 & 3.0 & 309.0 & 338.0 & 74.6 \\
\hline 18 & 31301-1 & 0.53 & 4.8 & 300.0 & 429.0 & 67.1 \\
\hline 19 & $31301-2$ & 0.52 & 5.1 & 300.0 & 379.1 & 70.1 \\
\hline 20 & $31303-3$ & 0.60 & 4.7 & 300.0 & 389.6 & 103.4 \\
\hline 21 & $31303-4$ & 0.62 & 4.5 & 300.0 & 388.5 & 109.2 \\
\hline 22 & 43115 & 0.51 & 2.3 & 360.0 & 101.6 & 74.0 \\
\hline 23 & 31401 & 0.61 & 4.4 & 300.0 & 235.0 & 87.1 \\
\hline 24 & 1203 & 0.48 & 4.0 & 135.0 & 49.0 & 69.0 \\
\hline 25 & 23101 & 0.49 & 3.0 & 300.0 & 327.0 & 75.5 \\
\hline 26 & 12610 & 0.57 & 5.0 & 200.0 & 135.0 & 99.5 \\
\hline 27 & 2301 & 0.56 & 3.6 & 130.0 & 143.5 & 70.0 \\
\hline 28 & 105 & 0.57 & 2.5 & 300.0 & 85.5 & 78.0 \\
\hline
\end{tabular}

This model has boundedness and proximity: $0<Y\left(X_{0}\right.$, $\left.X_{i}\right) \leq 1$; the smaller the $\left|x_{0}(k)-x_{i}(k)\right|$, the larger the $Y\left(x_{0}(k)\right.$, $\left.x_{i}(k)\right)$.

It should be noted that each influence factor is called subsequence, and the development height of the waterconducting fracture zone is called mother sequence. The greater the sensitivity coefficient is, the higher the sensitivity of the subsequence to the mother sequence is. When the sensitivity coefficient is 1 , the sensitivity is the highest.

4.2. Results Analysis. Based on the above mathematical model and data, the sensitivity coefficients of each subsequence to the mother sequence are solved. As shown in Figure 4, the sensitivity coefficient of mining thickness, ratio coefficient of hard rock lithology, mining depth, and length of working face is $0.75,0.69,0.66$, and 0.58 , respectively. The order of sensitivity coefficient is as follows: mining thickness $>$ ratio coefficient of hard rock lithology $>$ mining depth $>$ length of working face. This is consistent with the "three under" rules formula that mining thickness is the main factor affecting the development height of the water-conducting fracture zone and the literature [31] research results.

\section{Multiple Regression Analysis to Predict the Height of the Water-Conducting Fracture Zone}

The multiple regression analysis method is a mathematical method used to establish the relationship between statistical observations and then predict the value of dependent variable through the change of independent variable. When the linear relationship is satisfied between variables, it is called multiple linear regression. Many nonlinear problems can be transformed into linear problems to deal with [32].

The basic model of multiple linear regression is

$$
y=\beta_{0}+\beta_{1} x_{1}+\beta_{2} x_{2}+\cdots+\beta_{n} x_{n}
$$

The regression coefficient $\beta_{0}, \beta_{1}, \beta_{2}, \cdots$, and $\beta_{n}$ is calculated by the least square method, and solution is as follows:

$$
f\left(x_{i}\right)=\sum\left(y_{i}-\hat{y}_{i}\right)^{2}=\sum\left(y_{i}-\beta_{0}-\beta_{1} x_{1 i}-\beta_{2} x_{2 i}-\cdots-\beta_{n} x_{n i}\right)^{2}=\min ,
$$




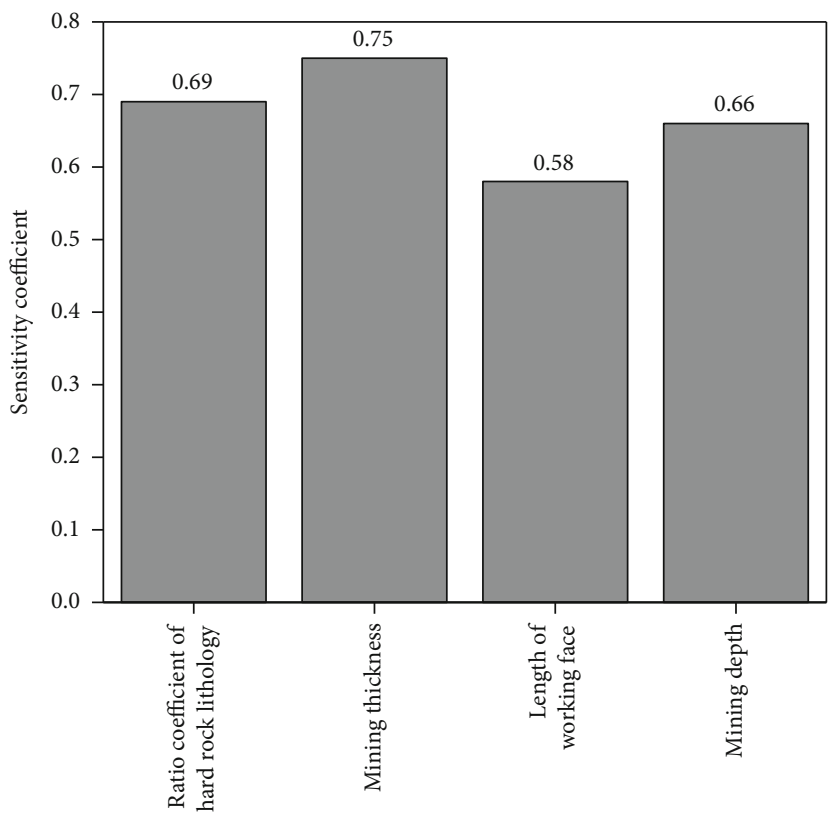

FIGURE 4: Sensitivity coefficient of influence factors.

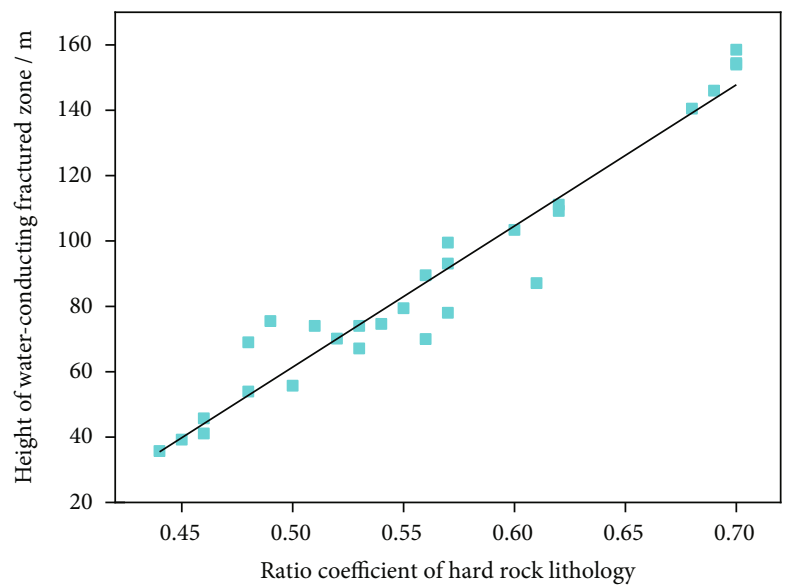

(a)

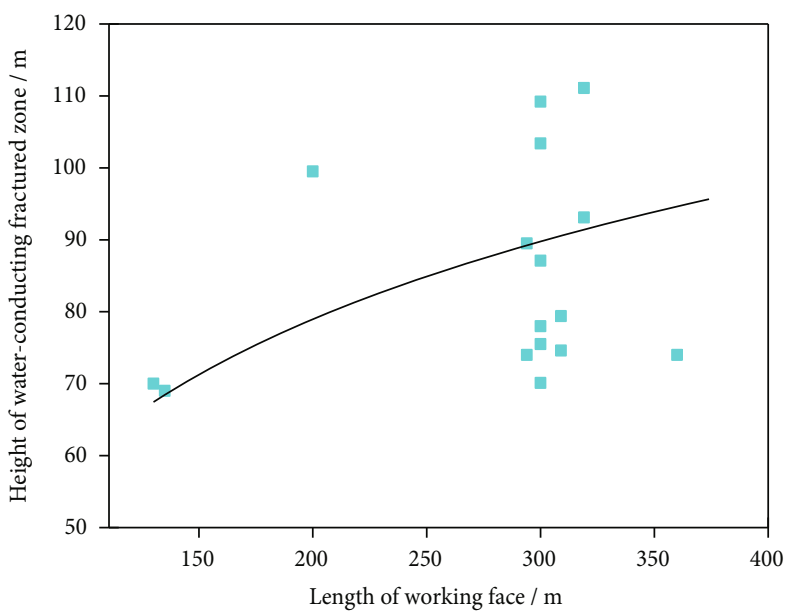

(c)

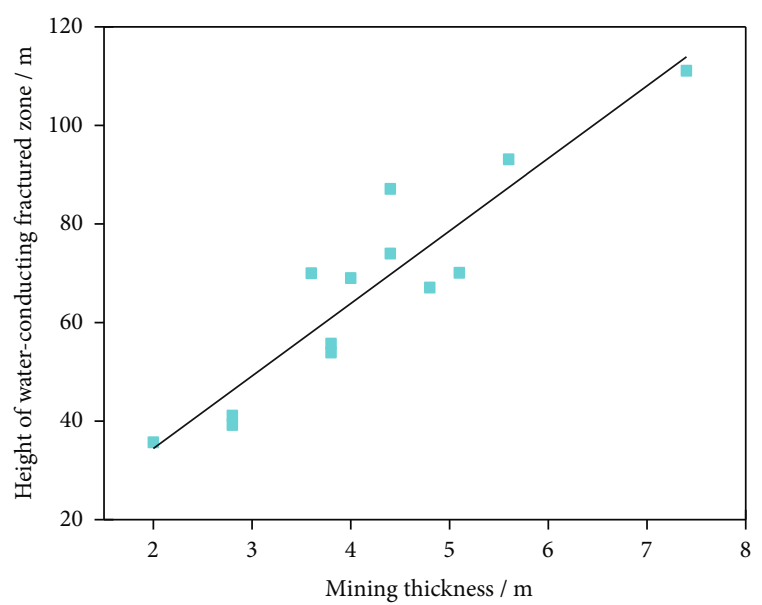

(b)

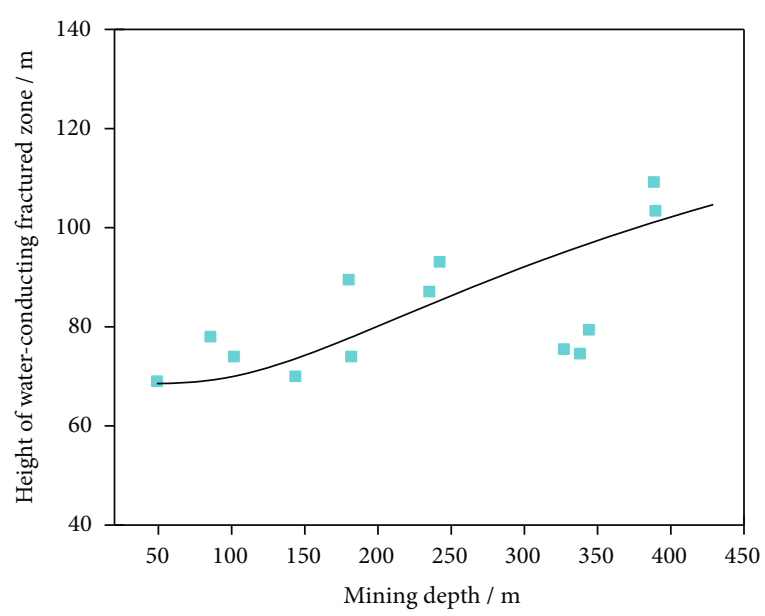

(d)

FIGURE 5: The relationship between the height of the water-conducting fracture zone and influence factors. 


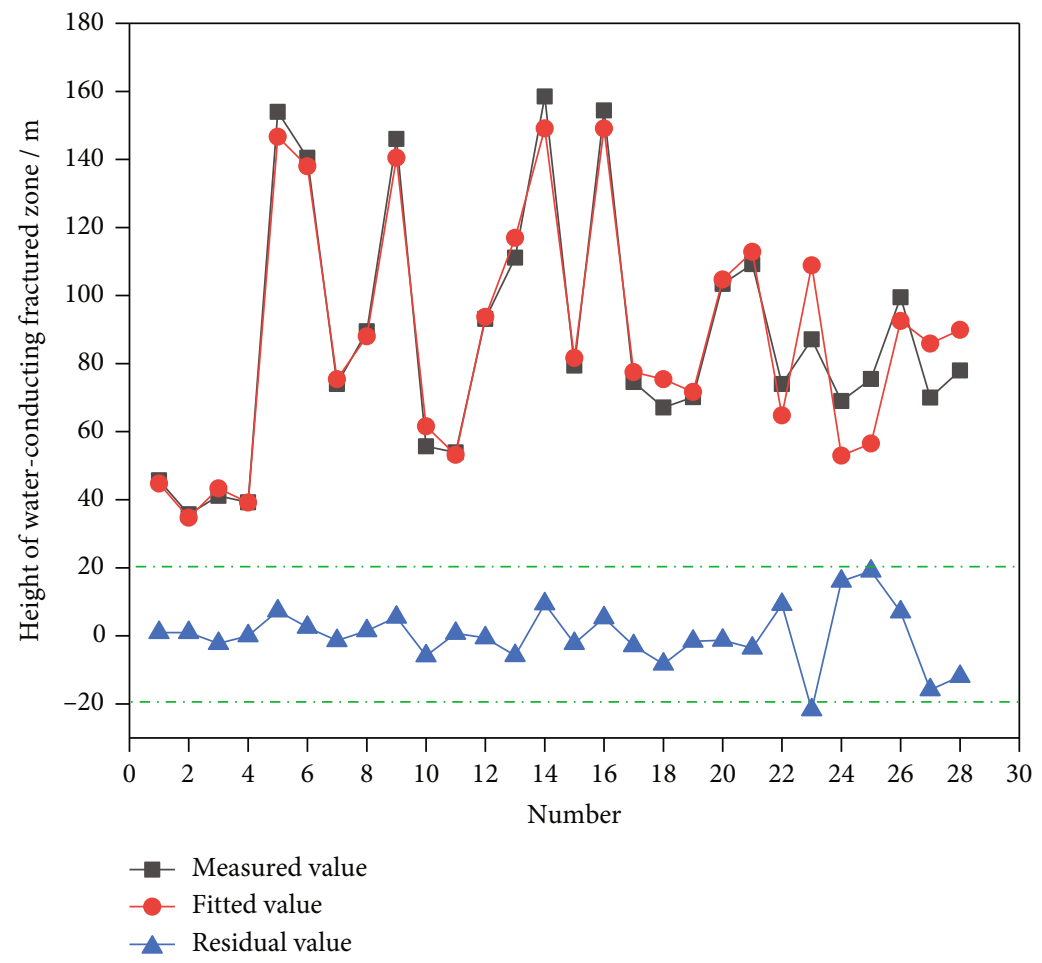

FIGURE 6: Residual error analysis of prediction formula.

TABLE 2: Empirical formula of the height of the water-conducting fracture zone [14].

\begin{tabular}{lrr}
\hline Lithology & Formula $(1) / \mathrm{m}$ & Formula $(2) / \mathrm{m}$ \\
\hline Hard & $H_{f}=\left(100 \sum M / 1.2 \sum M+2.0\right) \pm 8.9$ & $H_{f}=30 \sqrt{\sum M+10}$ \\
Medium hard & $H_{f}=\left(100 \sum M / 1.6 \sum M+3.6\right) \pm 5.6$ & $H_{f}=20 \sqrt{\sum_{M}+10}$ \\
Weak & $H_{f}=\left(100 \sum M / 3.1 \sum M+5.0\right) \pm 4.0$ & $H_{f}=10 \sqrt{\sum M+5}$ \\
Extremely weak & $H_{f}=\left(100 \sum M / 5.0 \sum M+8.0\right) \pm 3.0$ & \\
\hline
\end{tabular}

In the formula, the independent variable $x_{1 i}, x_{2 i}, \cdots, x_{n i}$ and the dependent variable $y_{i}$ are all known observations, and the regression coefficient is required to first derive $\beta_{0}$, $\beta_{1}, \beta_{2}, \cdots, \beta_{n}$ and then make the first derivative equal to 0 , and we get

$$
\left\{\begin{array}{l}
L_{11} \beta_{1}+L_{12} \beta_{2}+\cdots+L_{1 n} \beta_{n}=L_{1 y} \\
L_{21} \beta_{1}+L_{22} \beta_{2}+\cdots+L_{2 n} \beta_{n}=L_{2 y} \\
\vdots \\
L_{n 1} \beta_{1}+L_{n 2} \beta_{2}+\cdots+L_{n n} \beta_{n}=L_{n y}
\end{array} .\right.
$$

In the formula, $L_{i j}=L_{j i}=\sum\left(x_{i j}-\bar{x}_{i .}\right)\left(x_{i j}-\bar{x}_{. j}\right)$, and $L_{i y}$ $=\sum\left(x_{i j}-\bar{x}_{i .}\right)\left(y_{i}-\bar{y}_{i}\right)$.

Since $L_{i 1}, L_{i 2}, \cdots, L_{\text {in }}, L_{i y}(i=1,2, \cdots, n)$ is known, $x_{i j}, y_{i}$, $\bar{x}_{i .}, \bar{x}_{. j}, \bar{y}_{i}(i=1,2, \cdots, n)$ is also known, $\beta_{1}, \beta_{2}, \cdots, \beta_{\mathrm{n}}$ is $n$ unknowns, and there are $n$ equations. The determinant method can be used to obtain $\beta_{1}, \beta_{2}, \cdots, \beta_{n}$ and then get $\beta_{0}$.

To better predict the development height of the waterconducting fracture zone by multiple regression, the singlefactor regression analysis was carried out on the influencing factors and the development height of the water-conducting fracture zone. When other influence factors are similar, the DPS is used to select the representative data and perform single regression to obtain the single regression mathematical model with the largest correlation coefficient (Figure 5). From the data in the figure, it can be seen that the dispersion degree of working face length and mining depth is greater than that of ratio coefficient of hard rock lithology and mining thickness. To realize the quantitative analysis on the dispersion degree, the dispersion coefficient is introduced. The larger the dispersion coefficient is, the greater the degree of dispersion.

$$
V_{s}=\frac{s}{\bar{y}_{i}}
$$


TABLE 3: Relative error analysis.

\begin{tabular}{|c|c|c|c|c|c|c|}
\hline \multirow[t]{2}{*}{ Number } & \multirow{2}{*}{$\begin{array}{l}\text { Borehole number of } \\
\text { working face }\end{array}$} & \multirow{2}{*}{$\begin{array}{l}\text { Measured height of water- } \\
\text { conducting fracture zone } / \mathrm{m}\end{array}$} & \multicolumn{2}{|c|}{$\begin{array}{l}\text { “Three under” rules } \\
\text { empirical formula }\end{array}$} & \multicolumn{2}{|c|}{ Fitted formula } \\
\hline & & & Predicted value/m & Relative error/\% & Predicted value/m & Relative error $/ \%$ \\
\hline 1 & 93104 & 45.7 & 44.64 & 2.32 & 44.73 & 2.11 \\
\hline 2 & 12403 & 35.7 & 38.28 & -7.24 & 34.72 & 2.74 \\
\hline 3 & 22111-1 & 41.1 & 43.47 & -5.76 & 43.33 & -5.44 \\
\hline 4 & $22111-2$ & 39.2 & 43.47 & -10.88 & 39.17 & 0.08 \\
\hline 5 & $12401-1$ & 154.0 & 52.90 & 65.65 & 146.66 & 4.77 \\
\hline 6 & $12401-2$ & 140.5 & 51.95 & 63.02 & 138.02 & 1.77 \\
\hline 7 & $12406-1$ & 74.0 & 51.95 & 29.79 & 75.41 & -1.90 \\
\hline 8 & $12406-2$ & 89.5 & 51.95 & 41.95 & 88.00 & 1.68 \\
\hline 9 & 22101 & 146.0 & 44.64 & 69.42 & 140.50 & 3.77 \\
\hline 10 & $12304-1$ & 55.7 & 48.99 & 12.05 & 61.57 & -10.53 \\
\hline 11 & $12304-2$ & 53.9 & 48.99 & 9.11 & 53.18 & 1.34 \\
\hline 12 & $12511-1$ & 93.1 & 57.33 & 38.42 & 93.71 & -0.65 \\
\hline 13 & $12511-2$ & 111.1 & 64.41 & 42.03 & 116.94 & -5.25 \\
\hline 14 & 42106-1 & 158.5 & 61.38 & 61.27 & 149.09 & 5.94 \\
\hline 15 & 42106-2 & 79.4 & 44.64 & 43.78 & 81.67 & -2.86 \\
\hline 16 & 42106-3 & 154.4 & 61.38 & 60.25 & 149.09 & 3.44 \\
\hline 17 & 42106-4 & 74.6 & 44.64 & 40.16 & 77.49 & -3.87 \\
\hline 18 & 31301-1 & 67.1 & 53.82 & 19.79 & 75.41 & -12.38 \\
\hline 19 & $31301-2$ & 70.1 & 55.17 & 21.30 & 71.69 & -2.27 \\
\hline 20 & $31303-3$ & 103.4 & 53.36 & 48.40 & 104.71 & -1.27 \\
\hline 21 & $31303-4$ & 109.2 & 52.43 & 51.99 & 112.84 & -3.33 \\
\hline 22 & 43115 & 74.0 & 40.33 & 45.50 & 64.76 & 12.49 \\
\hline 23 & 31401 & 87.1 & 51.95 & 40.35 & 108.86 & -24.98 \\
\hline 24 & 1203 & 69.0 & 50.00 & 27.54 & 52.98 & 23.22 \\
\hline 25 & 23101 & 75.5 & 44.64 & 40.87 & 56.50 & 25.17 \\
\hline 26 & 12610 & 99.5 & 54.72 & 45.00 & 92.51 & 7.03 \\
\hline 27 & 2301 & 70.0 & 47.95 & 31.50 & 85.85 & -22.65 \\
\hline 28 & 105 & 78.0 & 41.62 & 46.64 & 89.93 & -15.30 \\
\hline
\end{tabular}

In the formula, $V_{s}$ is the dispersion coefficient, $\bar{y}_{i}$ is the average value, and $s$ is the standard deviation. Through the above formula (1), the dispersion coefficients of the regression model of mining thickness, ratio coefficient of hard rock lithology, mining depth, and working face length to the height of the water-conducting fracture zone are $0.15,0.17$, 0.33 , and 0.41 , respectively. To some extent, it also reflects that the sensitivity of working face length and mining depth to the height of the water-conducting fracture zone is the weakest, which is consistent with the previous conclusions. Through separate regression analysis of each factor and the height of the water-conducting fracture zone, we can obtain a good linear relationship between the development height of the water-conducting fracture zone and ratio coefficient of hard rock lithology and mining thickness, a natural logarithmic function relationship with working face length, and an exponential function relationship with mining depth.

Based on the DPS and above analysis, the ratio coefficient of hard rock lithology, mining thickness, working face length, and mining depth is comprehensively considered, and the curve fitting is carried out by multiple nonlinear regression, and the fitting formula is as follows:

$H_{\mathrm{f}}=419.41 b+1.29 M+1.46 \ln l-0.01 \mathrm{e}^{5.346-\frac{426.243}{s}}-160.67$.

In the formula, $H_{\mathrm{f}}$ is the development height of the water-conducting fracture zone, $\mathrm{m} ; b$ is the ratio coefficient of hard rock lithology; $M$ is the mining thickness, $\mathrm{m} ; l$ is the length of working face, $\mathrm{m}$; and $s$ is the mining depth, $\mathrm{m}$.

The residual value is obtained by using the fitting formula analysis, as shown in Figure 6. After several iterations, it can be seen that the residual value basically presents straight-line trend, reaching the convergence state, and indicating that the regression model is reliable. Relative error between the height of the water-conducting fracture zone predicted by empirical formula (2) (Table 2) and fitting regression formula is shown in Table 3. 
TABLE 4: Height prediction in a working face of the Shendong mining area.

\begin{tabular}{|c|c|c|c|c|}
\hline \multirow{2}{*}{$\begin{array}{l}\text { Measured } \\
\text { value } / \mathrm{m}\end{array}$} & \multicolumn{2}{|c|}{ Fitting formula } & \multicolumn{2}{|c|}{$\begin{array}{l}\text { "Three under" rules } \\
\text { empirical formula }\end{array}$} \\
\hline & $\begin{array}{l}\text { Predicted } \\
\text { value } / \mathrm{m}\end{array}$ & $\begin{array}{l}\text { Relative } \\
\text { error/\% }\end{array}$ & $\begin{array}{l}\text { Predicted } \\
\text { value/m }\end{array}$ & $\begin{array}{l}\text { Relative } \\
\text { error } / \%\end{array}$ \\
\hline 62.9 & 64.5 & -2.54 & 41.6 & 33.86 \\
\hline
\end{tabular}

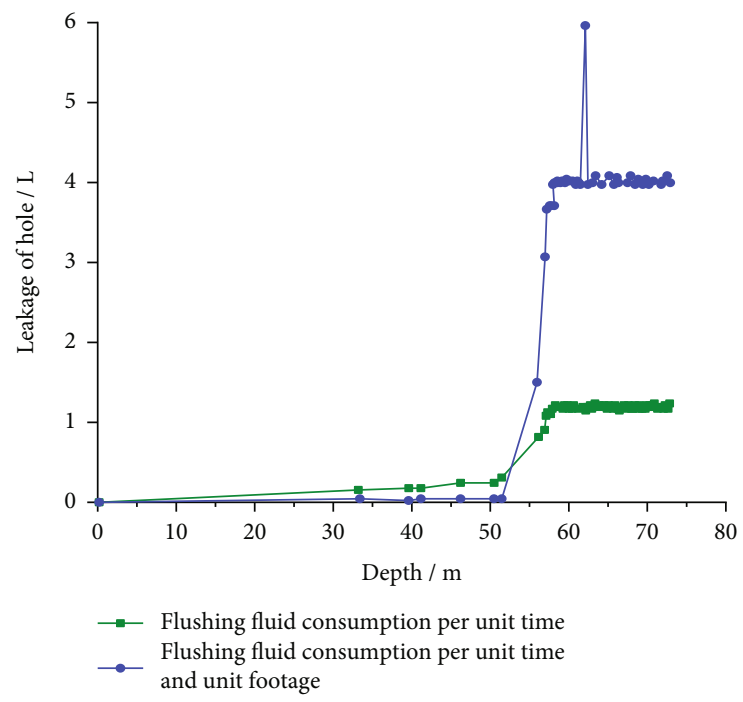

FIGURE 7: Flushing fluid consumption curve [33].

By analyzing the relative error between measured value and predicted value of the height of water-conducting fracture zone, it can be seen that the relative error has positive and negative values. A positive number indicates that the measured value is higher than the predicted value, and a negative number indicates that the measured value is lower than the predicted value. Relative error between the predicted value and the measured value calculated by the formula of "three under" rules is large, and the maximum is $69.42 \%$. Relative error between the predicted value and the measured value calculated by the fitting formula is small except for some data. Therefore, the height of the water-conducting fracture zone calculated by the fitting formula is more accurate. In the future, the water-conducting height should be determined based on the specific engineering geological conditions and appropriate fitting formula.

\section{Field Application}

Formula (9) is used to predict the height of the waterconducting fracture zone in the coal mine site, as shown in Table 4. In a working face of the Shendong mining area, ratio coefficient of hard rock lithology is 0.51 , mining thickness is $2.5 \mathrm{~m}$, length of working face is $297.5 \mathrm{~m}$, and mining depth is $116.8 \mathrm{~m}$. By substituting the above parameters into formula (9), the height of the water-conducting fracture zone is $64.5 \mathrm{~m}$. As shown in Figure 7, the amount of flushing fluid leakage increases significantly at $62.9 \mathrm{~m}$ and then tends to be flat. All losses are at $72.8 \mathrm{~m}$, and the variation trend of the unit time and unit footage losses is basically the same as the unit time losses. Through the above analysis, the measured development height of the water-conducting fracture zone is $62.9 \mathrm{~m}$.

The difference between the predicted value and the measured value is small, and the relative error is $-2.54 \%$. The relative error reached $33.86 \%$ by using the "three under" rules empirical formula, and the relative error is large, which further verifies the rationality of the fitting formula. Therefore, using the fitting formula to predict the development height of the water-conducting fracture zone in the Shendong mining area has certain reliability and accuracy, which provides reference and guidance for scientific prevention and control of mine water disaster.

\section{Conclusion}

(1) The ratio coefficient of hard rock lithology, mining thickness, length of working face, and mining depth was $0.69,0.75,0.58$, and 0.66 , respectively. It is concluded in the sensitivity ranking of each factor to the height of the water-conducting fracture zone: mining thickness $>$ ratio coefficient of hard rock lithology > mining depth $>$ length of working face

(2) The development height of the water-conducting fracture zone has a good linear relationship with ratio coefficient of hard rock lithology and mining thickness, a natural logarithmic function relationship with length of working face, and an exponential function relationship with mining depth

(3) The dispersion degree of working face length and mining depth was greater than that of ratio coefficient of hard rock lithology and mining thickness. Meanwhile, the sensitivity of working face length and mining depth to the height of the waterconducting fracture zone was the weakest

(4) The nonlinear relationship between the height of the water-conducting fracture zone and ratio coefficient of hard rock lithology, mining thickness, working face length, and mining depth was obtained. It was applied to predict water-conducting height in the Shendong mining area and has achieved good application effect, providing guidance for the prevention and control of coal mine water

\section{Data Availability}

The data used to support the findings of this research are included within the paper.

\section{Conflicts of Interest}

The authors declare that there are no conflicts of interest. 


\section{Acknowledgments}

This work was supported by The National Key R\&D Program of China (2016YFC0501100), the program of This study was supported by the State Key Laboratory of Water Resource Protection and Utilization in Coal Mining (GJNY18-77). The authors gratefully acknowledge the financial support of the abovementioned agencies.

\section{References}

[1] X. Li, W. He, and Z. Xu, "Study on law of overlying strata breakage and migration in downward mining of extremely close coal seams by physical similarity simulation," Advances in Civil Engineering, vol. 2020, 11 pages, 2020.

[2] B. Zhang, Y. C. Xu, J. H. Li, and B. Xiong, "Research on the "two-zone" heights of soft stratum working face with slicing full-mechanized caving mining," Journal of Mining Science and Technology, vol. 4, no. 6, pp. 515-523, 2019.

[3] Z. Q. Hu and C. Chen, "Impact of underground coal mining on land ecology and its restoration in windy and sandy region," Journal of Mining Science and Technology, vol. 1, no. 2, pp. 120-130, 2016.

[4] Q. S. Li, Z. H. Xu, Y. Zhang, and W. R. He, "Study on deformation and failure characteristics of overlying strata with thick loose layers and thin bedrock based on Hoek-Brown criterion," Journal of Mining Science and Technology, vol. 4, no. 5, pp. 417-424, 2019.

[5] F. H. Zhao, Y. Guo, H. F. Sun, and M. Yang, "Fuzzy comprehensive discriminant method for complex limestone aquifers in Xinzhi coal mine," Journal of Mining Science and Technology, vol. 4, no. 3, pp. 195-203, 2019.

[6] F. P. Cui, Q. Wu, Y. H. Lin, S. Q. Zhao, and Y. F. Ceng, "Prevention and control techniques \& methods for water disasters at coal mines in China," Journal of Mining Science and Technology, vol. 3, no. 3, pp. 219-228, 2018.

[7] J. M. Zhang, K. Zhang, Z. G. Cao, and Y. Zhang, "Study on mining-bursting simulation and height calculation method for water flowing fractured zone," Journal of China Coal Society, vol. 42, no. 6, pp. 1557-1564, 2017.

[8] J. L. Xu, X. Z. Wang, W. T. Liu, and Z. G. Wang, "Effects of primary key stratum location on height of water flowing fractured zone," Chinese Journal of Rock Mechanics and Engineering, vol. 28, no. 2, pp. 380-385, 2009.

[9] L. Q. Shi, H. Q. Xin, P. H. Zhai et al., "Calculating the height of water flowing fracture zone in deep mining," Journal of China University of Mining \& Technology, vol. 41, no. 1, pp. 37-41, 2012.

[10] X. P. Lai, F. Cui, J. T. Cao, Z. H. Lv, and Y. L. Kang, "Analysis on characteristics of overlying rock caving and fissure conductive water in top-coal caving working face at three soft coal seam," Journal of China Coal Society, vol. 42, no. 1, pp. 148154, 2017.

[11] D. M. Yang, W. B. Guo, and G. B. Zhao, "Height of waterconducting zone in longwall top-coal caving mining under thick alluvium and soft overburden," Journal of China Coal Society, vol. 44, no. 11, pp. 3308-3316, 2019.

[12] Q. S. Li, J. F. Ju, Z. G. Cao, F. Gao, and J. H. Li, “Suitability evaluation of underground reservoir technology based on the discriminant of the height of water flowing fractured zone," Journal of China Coal Society, vol. 42, no. 8, pp. 2116-2124, 2017.

[13] L. G. Wang, Z. S. Wang, J. H. Huang, and D. L. Zhou, "Prediction on the height of water flowing fractured zone for shallow seam covered with thin bedrock and thick windblown sand," Journal of Mining \& Safety Engineering, vol. 29, no. 5, pp. 607-612, 2012.

[14] State Bureau of Coal Industry, Rules for coal pillar reservation and coal pressure mining in buildings, water bodies, railways and main shafts, Coal Industry Press, Beijing, China, 2000.

[15] X. B. Li, F. L. He, B. B. Qin, K. Lv, and W. R. He, "Study on classification and support of surrounding rock of mining roadway in extremely close coal seams," Journal of Mining Science and Technology, vol. 5, no. 3, pp. 325-333, 2020.

[16] Z. Xu, Q. Li, and X. Li, “Overburden migration and failure characteristics in mining shallow buried coal seam with thick loose layer," Advances in Materials science and Engineering, vol. 2020, Article ID 9024751, 12 pages, 2020.

[17] Z. H. Xu, Q. S. Li, X. B. Li et al., "Structural evolution of overburden and surface damage caused by high-intensity mining with shallow depth," Journal of China Coal Society, vol. 45, no. 8, pp. 2728-2739, 2020.

[18] D. Liu, Z. Gu, R. Liang et al., "Impacts of pore-throat system on fractal characterization of tight sandstones," Geofluids, vol. 2020, Article ID 4941501, 17 pages, 2020.

[19] B. Chen, S. Zhang, Y. Li, Z. Li, and H. Zhou, "Physical simulation study of crack propagation and instability information discrimination of rock-like materials with faults," Arabian Journal of Geosciences, vol. 13, no. 18, 2020.

[20] J. Chen, J. Zhao, S. Zhang, Y. Zhang, F. Yang, and M. Li, “An experimental and analytical research on the evolution of mining cracks in deep floor rock mass," Pure and Applied Geophysics, vol. 177, no. 11, pp. 5325-5348, 2020.

[21] C. Zhu, M. He, M. Karakus, X. Cui, and Z. Tao, "Investigating toppling failure mechanism of anti-dip layered slope due to excavation by physical modelling," Rock Mechanics and Rock Engineering, vol. 53, no. 11, pp. 5029-5050, 2020.

[22] J. Xu, G. Dai, W. Gong, Q. Zhang, A. Haque, and R. P. Gamage, "A review of research on the shaft resistance of rock-socketed piles," Acta Geotechnical, vol. 16, no. 3, pp. 653-677, 2021.

[23] H. B. Chai, J. P. Zhang, and C. Yan, "Height prediction of water flowing fracture zone in mining overlying rock based on GA-SVR," Journal of Mining \& Safety Engineering, vol. 35, no. 2, pp. 359-365, 2018.

[24] J. P. Zhang, Research on Development Law and Prediction Method of Overburden Cracks in Coal Seam Mining in Shendong Mining Area, [Ph.D. thesis], Henan Polytechnic University, 2017.

[25] X. Z. Wang, J. L. Xu, H. K. Han, J. F. Ju, and Y. T. Xing, "Stepped development characteristic of water flowing fracture height with variation of mining thickness," Journal of China Coal Society, vol. 44, no. 12, pp. 3740-3749, 2019.

[26] Y. Zhang, S. G. Cao, S. Guo, T. Wan, and J. J. Wang, "Study on the height of fractured water-conducting zone under aquifer for short wall blocking mining," Journal of Mining \& Safety Engineering, vol. 35, no. 2, pp. 106-111, 2018.

[27] D. T. Cao and W. P. Li, "Estimation method for height of fractured zone with water flowing in coal mining area," Chinese Journal of Geological Disasters and Prevention, vol. 25, no. 1, pp. 63-69, 2014. 
[28] S. S. Peng, H. M. Li, and Y. Zhou, "Research on rock layer control," in Shendong and Jungar mining areas, pp. 365-366, Science Press, Beijing, China, 2015.

[29] L. Q. Zhao, Study on the Failure Characteristics of Overburden in Fully Mechanized Mining of Extra Thick Coal Seam in Bulianta Coal Mine, [Ph.D. thesis], Coal Science Research Institute, 2018.

[30] W. B. Guo and G. Z. Lou, "Definition and distinguishing method of critical mining degree of overburden failure," Journal of China Coal Society, vol. 44, no. 3, pp. 755-766, 2019.

[31] Y. G. Wang, Study on Failure Characteristics and Mechanism of Overburden in High-strength Mining, [Ph.D. thesis], Henan Polytechnic University, 2016.

[32] X. J. Hu, W. P. Li, D. T. Cao, and M. C. Liu, "Index of multiple factors and expected height of fully mechanized water flowing fractured zone," Journal of China Coal Society, vol. 37, no. 4, pp. 613-620, 2012.

[33] D. Z. Gu, Q. S. Li, and A. M. He, Protection and Utilization of Water Resources in the "Golden Triangle" Coal Development, Science Press, Beijing, China, 2012. 